\title{
EFFECTS OF DIFFERENT AIRBORNE PARTICLE ABRASION PROTOCOLS ON THE SURFACE ROUGHNESS AND SHEAR BONDING STRENGTH OF HIGH/ULTRA-TRANSLUCENT ZIRCONIA TO RESIN CEMENT
}

\author{
"REEM ALMUTAIRI, AHMED ELHEJAZI, HEND ALNAHEDH, AND AHMED MAAWADH \\ Department of Restorative Dental Sciences, College of Dentistry, \\ King Saud University, Riyadh, Saudi Arabia \\ \#E-mail: reemalmutairi.993@gmail.com
}

Submitted August 5, 2021; accepted October 21, 2021

\begin{abstract}
Keywords: Ceramic, Aluminium Oxide, Bond, Glass, Particle, Translucent, Surface Treatment
This study evaluated the surface roughness and shear bond strength (SBS) of highly/ultra-translucent monolithic zirconia ceramics subjected to different mechanical surface pre-treatments. A total of 225 square samples of three zirconia materials (KATANA Zirconia UTML (ML), DD Bio ZX2 (DB), and DD cube X2 (DC)) were used. The surface roughness and SBS values of the materials with respect to a resin cement (Panavia V5) were investigated after subjecting the samples to surface treatments using air abrasion particles of two types (aluminium oxide or glass microbeads) and sizes $(50$ or $110 \mu \mathrm{m})$. The data were analysed using a two-way analysis of variance, followed by Tukey's post-hoc test for multiple comparisons. The highest mean surface roughness of the DC and ML ceramics were obtained after abrasion with the $110-\mu m \mathrm{Al}_{2} \mathrm{O}_{3}$ particles $(2.954 \pm 0.266 \mu \mathrm{m}$ and $2.850 \pm 0.296 \mu \mathrm{m}$, respectively). The mean $S B S$ values of the $D B, D C$, and $M L$ ceramics could be arranged in the following order based on the treatments: 110- $\mu \mathrm{m} \mathrm{Al}_{2} \mathrm{O}_{3}$ particles, 50- $\mu \mathrm{m} \mathrm{Al}_{2} \mathrm{O}_{3}$ particles, 110- $\mu \mathrm{m}$ glass microbeads, 50- $\mu \mathrm{m}$ glass microbeads, and the control. The combination of air abrasion with the 50- $\mu_{m} \mathrm{Al}_{2} \mathrm{O}_{3}$ particles and treatment with a 10-MDP primer resulted in the most durable bonding of the zirconia ceramics.
\end{abstract}

\section{INTRODUCTION}

Zirconia ceramics are among the most commonly used materials in restorative dentistry because of their high mechanical strength and acceptable aesthetic properties [1]. Zirconia ceramics are used as either monolithic ceramics or as core materials layered with other aesthetic ceramic materials. However, compared with silica-based ceramic restorations, restorations based on zirconia exhibit lower translucency and inferior aesthetics. This has limited their applicability in the anterior area. Their lower translucency is attributable to the absence of a glass matrix in the dense, sintered polycrystalline zirconia microstructure [2].

To overcome this shortcoming and improve the aesthetics, new zirconia materials with greater translucency have been introduced on the market. The first generation of such materials consisted of $3 \mathrm{~mol}$. \% (5.2 wt. \%) yttriastabilised tetragonal zirconia polycrystals (3Y-TZP) and contained 0.25 wt. $\%$ alumina $\left(\mathrm{Al}_{2} \mathrm{O}_{3}\right)$ [3]. The next generation of $3 \mathrm{Y}-\mathrm{TZP}$ exhibited reduced porosity, which was achieved by increasing the firing temperature and decreasing the amount of alumina present within the material $[4,5]$. These improvements resulted in 3Y-TZP with a higher translucency, and this material is referred to by manufacturers as highly translucent zirconia. The third generation of highly translucent ceramics had an yttria content of 5 mol. \% (5Y-TZP), and these materials are referred to as ultra-translucent zirconia or superhigh-translucent zirconia. Finally, the fourth-generation materials include zirconia with an yttria content of 4 mol. \% (4Y-TZP) to enhance the mechanical properties [6]. Both the third- and fourth-generation materials contain a larger amount of the cubic phase, which gives the materials their superior translucency [3].

Air abrasion is the standard treatment for altering the internal surface of zirconia in order to increase its mechanical retention [7]. Kern et al. [8] showed that the best treatment for ensuring durable adhesion between zirconia and resin cement is to combine airborne particle sandblasting using alumina particles with a size of $50 \mu \mathrm{m}$ at a pressure of $0.25 \mathrm{MPa}$ and the subsequent application of a 10-methacryloyloxydecyl dihydrogen phosphate (10-MDP)-containing monomer or a luting resin cement [8]. Two published meta-analyses have confirmed the importance of this combined mechanochemical surface treatment for improving the bond strength of zirconia with resin cements [9, 10]. Tanis and Akcaboy [11] reported that the air-particle abrasion of 3Y-TZP zirconia and the subsequent application of a 10-MDP-based luting resin cement is an effective approach for increasing the bond strength. Byeon et al. showed that the air-particle abrasion of 4Y-TZP followed by the use of a 10-MDP primer improves the bond strength of the zirconia to resin cement [12]. 
Currently, there is limited information regarding effective protocols for the bonding of resin cements to zirconia substrates that result in an acceptable bonding behaviour [13, 14]. Moreover, data regarding the shear bond strength of the new highly translucent zirconia ceramics to resin cements are also limited.

The aim of this study was to evaluate the surface roughness and shear bond strength (SBS) values of highly translucent and ultra-translucent monolithic zirconia ceramics subjected to different mechanical surface treatment protocols. Two null hypotheses were tested: (1) the surface roughness of the highly translucent and ultra-translucent zirconia ceramics is not affected by air abrasion surface treatments with aluminium oxide particles or glass microbeads; and (2) the SBS of translucent zirconia ceramics and resin cements is not affected by these mechanical surface pre-treatments.

\section{EXPERIMENTAL}

\section{Sample preparation}

Table 1 lists all the materials used in this study.

A total of 225 square zirconia samples $(8 \mathrm{~mm}$ in length $\times 8 \mathrm{~mm}$ in width $\times 3 \mathrm{~mm}$ in height) were used. First, the samples were prepared from pre-sintered zirconia blocks (KATANA Zirconia UTML, abbreviated as ML, Kuraray Noritake Dental, Tokyo, Japan), (DD
Bio ZX2, abbreviated as DB, Dental Direkt Materials, Germany) and (DD cube X2, abbreviated as DC, Dental Direkt Materials, Germany) using computer-aided design (CAD)/computer-aided manufacturing (CAM) (DWOS, Dental Wings, Montreal, Canada). Next, these CAD/CAM-shaped samples were sectioned into smaller ones with the above-mentioned dimensions using a lowspeed cutting machine (IsoMet 2000, Buehler, USA). All the samples were sintered as per the respective manufacturer's recommendations, as shown in Table 2. Both sides of the samples were polished with 600 grit silicon carbide paper and then with 1200 grit paper under wet conditions for $15 \mathrm{~s}$ [15]. The samples were then cleaned ultrasonically in distilled water for $10 \mathrm{~min}$ and then air-dried. The dried samples were divided into 15 subgroups according to the surface pre-treatment performed (air abrasion using particles of different types and sizes), as shown in Figure 1.

- Control group: No surface treatment

- DB1, DC1, and ML1 groups: Air abraded using 50- $\mu \mathrm{m} \mathrm{Al}_{2} \mathrm{O}_{3}$ particles

- DB2, DC2, and ML2 groups: Air abraded using $110-\mu \mathrm{m} \mathrm{Al}_{2} \mathrm{O}_{3}$ particles

- DB3, DC3, and ML3 groups: Air abraded using 50- $\mu \mathrm{m}$ glass microbeads

- DB4, DC4, and ML4 groups: Air abraded using $110-\mu \mathrm{m}$ glass microbeads

Table 1. Materials included in this study.

\begin{tabular}{lccll}
\hline Material & Brand name & Shade & Composition & Manufacturer \\
\hline $\begin{array}{l}\text { Highly translucent } \\
\text { 3Y-TZP ceramic }\end{array}$ & DD Bio ZX2 & White & $\begin{array}{l}\geq 99 \% \mathrm{ZrO}_{2}+\mathrm{HfO}_{2}+\mathrm{Y}_{2} \mathrm{O}_{3},<6 \mathrm{Y}_{2} \mathrm{O}_{3}, \\
\leq 0.15 \mathrm{Al}_{2} \mathrm{O}_{3},<1.0 \text { other oxides }\end{array}$ & $\begin{array}{l}\text { Dental Direkt Materials, } \\
\text { Germany }\end{array}$ \\
$\begin{array}{l}\text { Superhigh-translucence } \\
\text { 5Y-TZP ceramic }\end{array}$ & DD Cube X2 & \multirow{2}{*}{ White } & $\begin{array}{l}\geq 99 \% \mathrm{ZrO}_{2}+\mathrm{HfO}_{2}+\mathrm{Y}_{2} \mathrm{O}_{3},<10 \mathrm{Y}_{2} \mathrm{O}_{3}, \\
\leq 0,01 \mathrm{Al}_{2} \mathrm{O}_{3},<1,0 \text { other oxides }\end{array}$ & $\begin{array}{l}\text { Dental Direkt Materials, } \\
\text { Germany }\end{array}$ \\
$\begin{array}{l}\text { Ultra-translucence } \\
\text { 5Y-TZP ceramic }\end{array}$ & $\begin{array}{c}\text { KATANA zirconia } \\
\text { UTML }\end{array}$ & \multirow{2}{*}{ White } & $\begin{array}{l}87-92 \% \mathrm{ZrO}_{2}, 8-11 \% \mathrm{Y}_{2} \mathrm{O}_{3}, \\
\text { Other less than 2\% }\end{array}$ & $\begin{array}{l}\text { Kuraray Noritake } \\
\text { Dental, Tokyo, Japan }\end{array}$ \\
\hline
\end{tabular}

Bis-GMA, TEGDMA, Hydrophobic aromatic dimethacrylate, hydrophilic aliphatic

Self-adhesive dual-cure resin cement

PANAVIA V5

Clear dimethacrylate, Initiators, Accelerators, Silanated barium glass filler, Silanated fluoroaluminosilicate glass filler, Colloidal silica, Silanated aluminium oxide filler, DL-Camphorquinone, Pigments

\begin{tabular}{|c|c|c|c|c|}
\hline Primer & $\begin{array}{l}\text { CLEARFIL } \\
\text { Ceramic Primer } \\
\text { Plus }\end{array}$ & - & $\begin{array}{l}\text { 3-methacryloxypropyl trimethoxysilane, } \\
\text { 10-methacryloyloxydecyl dihydrogen } \\
\text { phosphate (MDP), Ethanol }\end{array}$ & $\begin{array}{l}\text { Kuraray Noritake } \\
\text { Dental, Tokyo, Japan }\end{array}$ \\
\hline $\begin{array}{l}50-\text { and } 110-\mu \mathrm{m} \\
\text { glass beads microbeads } \\
\text { particles }\end{array}$ & Rolloblast & - & Glass microbeads & Renfert, Germany \\
\hline $\begin{array}{l}50 \text { - and } 110-\mu \mathrm{m} \\
\text { aluminium oxide } \\
\text { particles }\end{array}$ & Cobra & - & Aluminium oxide & Renfert, Germany \\
\hline
\end{tabular}

Note: $\mathrm{ZrO}_{2}$ : zirconium dioxide, $\mathrm{HfO}_{2}$ : hafnium dioxide, $\mathrm{Y}_{2} \mathrm{O}_{3}:$ yttrium oxide, $\mathrm{Al}_{2} \mathrm{O}_{3}$ : aluminium oxide, Bis-GMA: bisphenol A-glycidyl methacrylate; TEGDMA: triethylene glycol dimethacrylate 
The air abrasion procedure was performed using a sandblaster (Duostar Plus, BEGO, Germany) [15-17] under a standardised pressure of 2 bar. The nozzle was placed at an angle of $90^{\circ}$ from the centre of the sample at a distance of $10 \mathrm{~mm}$, and the sample was abraded for $20 \mathrm{~s}$.

Table 2. Sintering conditions for the zirconia ceramics used in this study.

\begin{tabular}{lcc}
\hline Material (brand name) & $\begin{array}{c}\text { Sintering } \\
\text { temperature }\end{array}$ & $\begin{array}{c}\text { Holding } \\
\text { time }\end{array}$ \\
\hline DD Bio ZX2 & $1450{ }^{\circ} \mathrm{C}$ & $9 \mathrm{~h}$ \\
DD Cube X2 & $1450{ }^{\circ} \mathrm{C}$ & $9 \mathrm{~h}$ \\
KATANA zirconia UTML & $1550{ }^{\circ} \mathrm{C}$ & $2 \mathrm{~h}$ \\
\hline
\end{tabular}

\section{Measurement of surface roughness}

Five samples from each of the 15 zirconia subgroups were randomly selected using electronic randomisation software (Stata, StataCorp, USA). The selected samples were ultrasonically cleaned with distilled water for $10 \mathrm{~min}$ and then air-dried. The surface roughness $\left(\mathrm{R}_{\mathrm{a}}\right)$ was determined using a non-contact profilometer (ContourGT-X 3D Optical Profiler, Bruker, USA). A $5 \times$ Michelson magnification lens with a field of view of $1.5 \times 1.5 \mathrm{~mm}$, scan speed of $1 \times$, and threshold of 4 was used. The sample was placed on the stage and manually adjusted to obtain an image on the monitor screen. The microscope used Vision $64^{\circledR}$ software (Bruker), which allows one to control the instrument settings, perform the data analyses, and obtain the graphical output. Vertical scanning interferometry, which uses a broadband light source, was used for the analysis. A total of three three-dimensional surface roughness measurements were performed on each sample. The arithmetic mean $\left(\mathrm{S}_{\mathrm{a}}\right)$ of the three measurements was obtained in micrometres, and the changes in the mean surface roughness of each sample after the surface pre-treatments were determined.
Measurement of shear bond strength

(SBS) and analysis of failure type

A total of 225 square samples ( $n=75$ for each zirconia subgroup) were embedded in a self-curing acrylic resin (Takilon, Rodent s.r.l., Milan, Italy), ultrasonically cleaned with $99 \%$ isopropanol for $180 \mathrm{~s}$, and air-dried. A piece of polyethylene tape with a thickness of $50 \mu \mathrm{m}$ and having a hole with a diameter of $2 \mathrm{~mm}$ was positioned on the zirconia samples to control the bonding area. A ceramic primer (CLEARFIL $^{\mathrm{TM}}$ Ceramic Primer Plus, Kuraray Noritake Dental, Tokyo, Japan) was applied once on all the samples using a regular-sized disposable applicator (Microbrush, Microbrush International, USA) and blow-dried with air. To define the bonding area, silicon moulds with a diameter of $2 \mathrm{~mm}$ and length of $2 \mathrm{~mm}$ were fabricated [18]. A self-adhesive dual-cure resin cement (Panavia V5, Kuraray Noritake Dental, Tokyo, Japan) was applied directly on the fabricated silicon moulds at the centre of the zirconia samples using a mixing tip. The excess cement was removed using a regular-sized microbrush (Microbrush International, USA). Polymerisation was performed for $40 \mathrm{~s}$ (10 s per side) using a light-emitting diode unit (Bluephase, Ivoclar Vivadent, Schaan, Liechtenstein) with an intensity of $1400 \mathrm{~mW} \cdot \mathrm{cm}^{-2}$. The bonded samples were stored in distilled water for $24 \mathrm{~h}$ at $37^{\circ} \mathrm{C}$ before being subjected to thermocycling. The samples were then subjected to artificial ageing by thermocycling for 5000 cycles alternately at 5 and $55{ }^{\circ} \mathrm{C}$ in water baths for $15 \mathrm{~s}$ each (CS-4.2, THE-1100, SD-Mechatronik, Germany); the transfer time was 5 s [19]. For the SBS measurements, each bonded sample was placed in a shear-bond testing jig (Tokyo Giken Inc., Tokyo, Japan) per ISO TR11405. The sample was then subjected to a knife edge SBS test using a mechanical testing machine (Type 5567, Instron, Canton, MA, USA) at $5 \mathrm{kN}$ and a crosshead speed of $0.5 \mathrm{~mm} \cdot \mathrm{min}^{-1}$, and the shear load $(\mathrm{N})$ at the

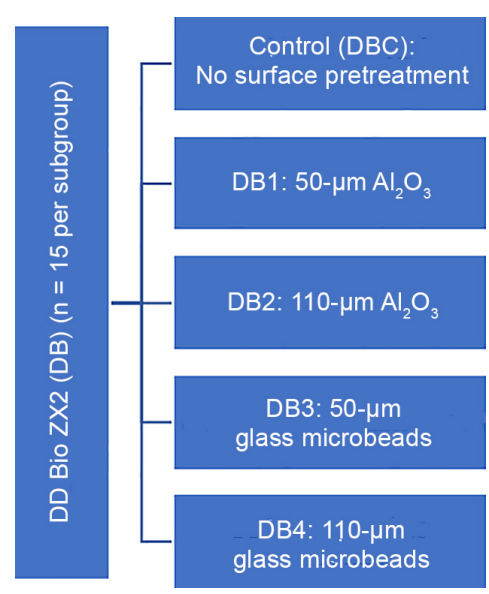

a)

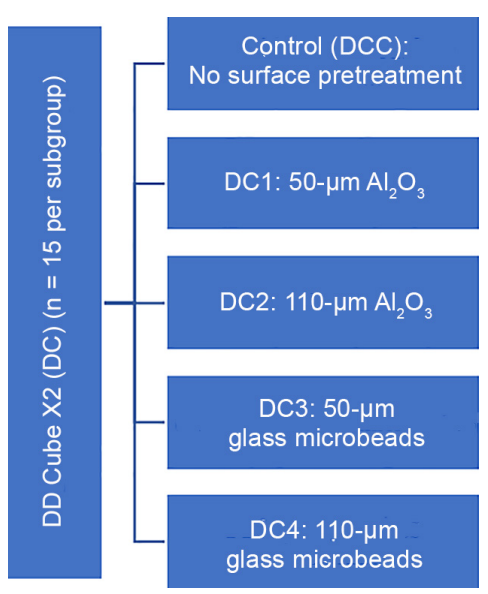

b)

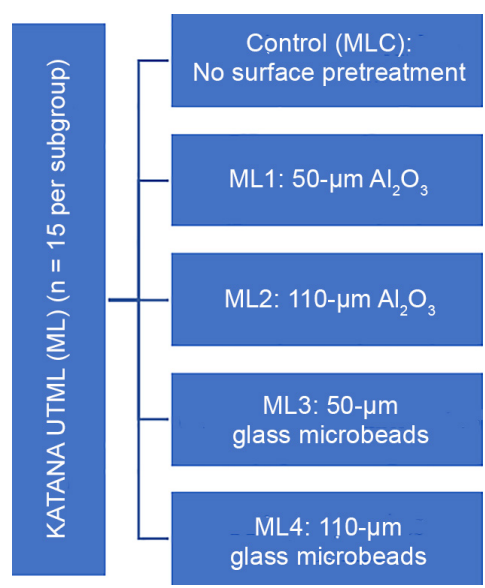

c)

Figure 1. Schematic representation of the study design. Different zirconia ceramics were subjected to surface pre-treatments involving air abrasion with particles of different types and sizes and their surface roughness and shear bond strength (SBS) values were determined (DB: DD Bio ZX2 ceramic material; DC: DD Cube X2 ceramic material; ML: KATANA UTML ceramic material). 
moment of failure was recorded. The measured SBS value was converted from Newtons into mega Pascals by dividing the load at failure $(\mathrm{N})$ by the cross-sectional interfacial area $\left(\mathrm{mm}^{2}\right)[16,18,19]$. To detect the failure modes, the debonded samples were evaluated using a digital microscope (KH-7700, Hirox, Tokyo, Japan) at a magnification of $50 \times$. The failure modes were categorised as adhesive failure (failure between the zirconia material and resin cement), cohesive failure (failure within the zirconia material or resin cement), or mixed failure (a mix of adhesive and cohesive failure) [18].

\section{Statistical analysis}

The data were collected and grouped for statistical analyses using the statistical software package SPSS (version 23). A statistical analysis was performed using the Shapiro-Wilk test for normal distributions $(p>0.05)$. A two-way analysis of variance (ANOVA) was performed to evaluate the null hypotheses. This was followed by Tukey's post-hoc tests for multiple comparisons ( $p<$ 0.05 ). The level of significance was set at $\mathrm{p} \leq 0.05$ while the statistical significance was set at $\mathrm{P} \leq 0.05$.

\section{RESULTS}

The mean $( \pm \mathrm{SD})$ surface roughness of DD Bio ZX2 (DB) was the highest after it had been subjected to air abrasion using the $50-\mu \mathrm{m} \mathrm{Al}_{2} \mathrm{O}_{3}$ particles $(3.134$ $\pm 0.359 \mu \mathrm{m})$ and the lowest after the treatment with the $50-\mu \mathrm{m}$ glass microbeads $(0.436 \pm 0.283 \mu \mathrm{m})$. In the cases of DD Cube X2 (DC) and KATANA UTML (ML), it was the highest after the treatment with the $110-\mu \mathrm{m} \mathrm{Al}_{2} \mathrm{O}_{3}$

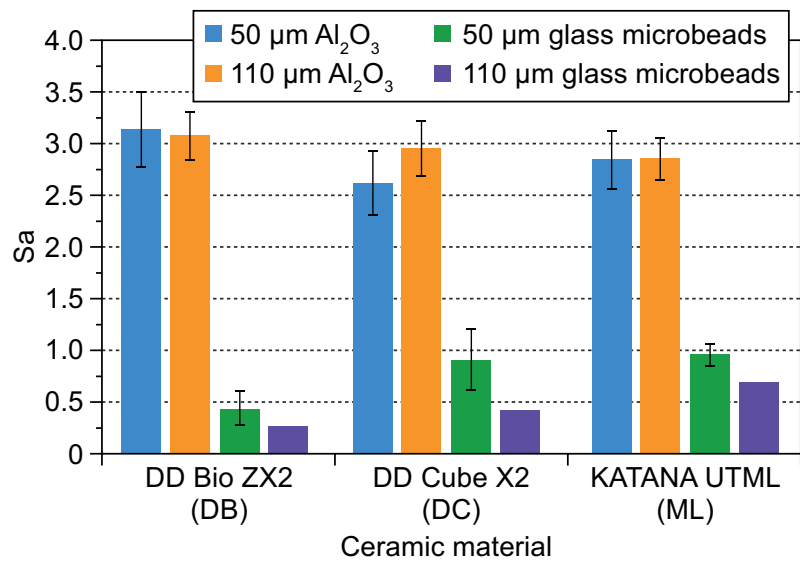

Figure 2. Mean surface roughness $(\mu \mathrm{m})$ of the various experimental groups.

Table 3. Mean (and SD) surface roughness values $(\mu \mathrm{m})$ of the various experimental groups.

\begin{tabular}{|c|c|c|c|c|c|c|c|c|c|}
\hline & & \multirow{2}{*}{ Mean } & \multirow{2}{*}{$\begin{array}{c}\text { Std. } \\
\text { deviation }\end{array}$} & \multirow{2}{*}{$\begin{array}{l}\text { Std. } \\
\text { error }\end{array}$} & \multicolumn{2}{|c|}{$\begin{array}{l}95 \% \text { Confidence } \\
\text { interval for mean }\end{array}$} & \multirow{2}{*}{ Minimum } & \multirow{2}{*}{ Maximum } & \multirow{2}{*}{$\mathrm{p}$ value } \\
\hline & & & & & $\begin{array}{l}\text { Lower } \\
\text { bound }\end{array}$ & $\begin{array}{l}\text { Upper } \\
\text { bound }\end{array}$ & & & \\
\hline \multirow{4}{*}{$\begin{array}{l}\text { DD Bio ZX2 } \\
\text { (DB) }\end{array}$} & $\begin{array}{c}50-\mu \mathrm{m} \mathrm{Al}_{2} \mathrm{O}_{3} \\
\text { particles }\end{array}$ & 3.134 & 0.359 & 0.161 & 2.688 & 3.580 & 2.766 & 3.608 & \multirow{4}{*}{$0.000 *$} \\
\hline & $\begin{array}{c}110-\mu \mathrm{m} \mathrm{Al}_{2} \mathrm{O}_{3} \\
\text { particles }\end{array}$ & 3.072 & 0.307 & 0.137 & 2.691 & 3.453 & 2.692 & 3.436 & \\
\hline & $\begin{array}{l}50-\mu \mathrm{m} \text { glass } \\
\text { microbeads }\end{array}$ & 0.436 & 0.283 & 0.126 & 0.084 & 0.787 & 0.207 & 0.927 & \\
\hline & $\begin{array}{c}110-\mu \mathrm{m} \text { glass } \\
\text { microbeads }\end{array}$ & 0.438 & 0.144 & 0.064 & 0.259 & 0.617 & 0.288 & 0.647 & \\
\hline \multirow{4}{*}{$\begin{array}{l}\text { DD Cube X2 } \\
\text { (DC) }\end{array}$} & $\begin{array}{c}50-\mu \mathrm{m} \mathrm{Al}_{2} \mathrm{O}_{3} \\
\text { particles }\end{array}$ & 2.625 & 0.232 & 0.104 & 2.337 & 2.914 & 2.230 & 2.803 & \multirow{4}{*}{$0.000 *$} \\
\hline & $\begin{array}{c}110-\mu \mathrm{m} \mathrm{Al}_{2} \mathrm{O}_{3} \\
\text { particles }\end{array}$ & 2.954 & 0.266 & 0.119 & 2.624 & 3.284 & 2.682 & 3.267 & \\
\hline & $\begin{array}{l}50-\mu \mathrm{m} \text { glass } \\
\text { microbeads }\end{array}$ & 0.910 & 0.202 & 0.090 & 0.660 & 1.161 & 0.630 & 1.140 & \\
\hline & $\begin{array}{l}110-\mu \mathrm{m} \text { glass } \\
\text { microbeads }\end{array}$ & 0.413 & 0.126 & 0.056 & 0.257 & 0.570 & 0.284 & 0.604 & \\
\hline \multirow{4}{*}{$\begin{array}{l}\text { KATANA } \\
\text { UTML (ML) }\end{array}$} & $\begin{array}{c}50-\mu \mathrm{m} \mathrm{Al}_{2} \mathrm{O}_{3} \\
\text { particles }\end{array}$ & 2.840 & 0.166 & 0.074 & 2.634 & 3.045 & 2.724 & 3.127 & \multirow{4}{*}{$0.000^{*}$} \\
\hline & $\begin{array}{c}110-\mu \mathrm{m} \mathrm{Al}_{2} \mathrm{O}_{3} \\
\text { particles }\end{array}$ & 2.850 & 0.296 & 0.132 & 2.483 & 3.218 & 2.481 & 3.184 & \\
\hline & $\begin{array}{l}50-\mu \mathrm{m} \text { glass } \\
\text { microbeads }\end{array}$ & 0.954 & 0.107 & 0.048 & 0.821 & 1.087 & 0.847 & 1.086 & \\
\hline & $\begin{array}{l}110-\mu \mathrm{m} \text { glass } \\
\text { microbeads }\end{array}$ & 0.700 & 0.118 & 0.053 & 0.553 & 0.847 & 0.563 & 0.848 & \\
\hline
\end{tabular}

* Statistically significant at $P \leq 0.05$. 


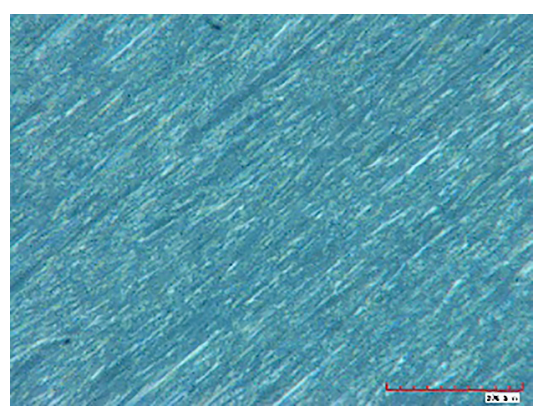

a) control (DBC) group

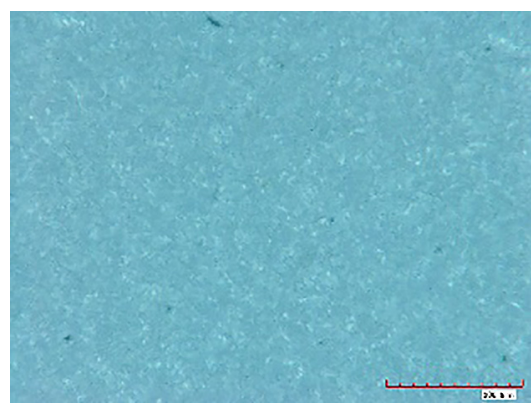

d) DB1 group

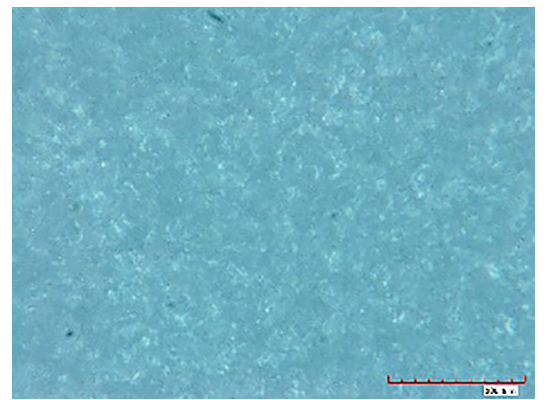

g) DB2 group

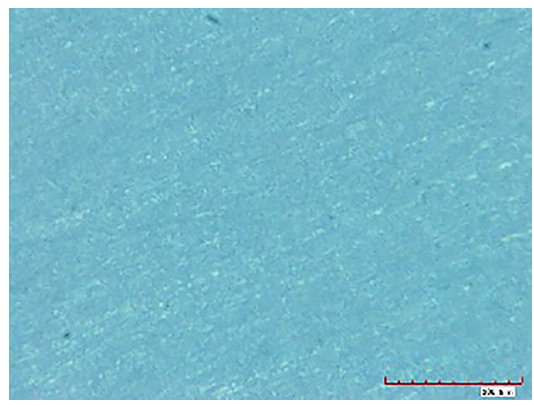

j) DB3 group

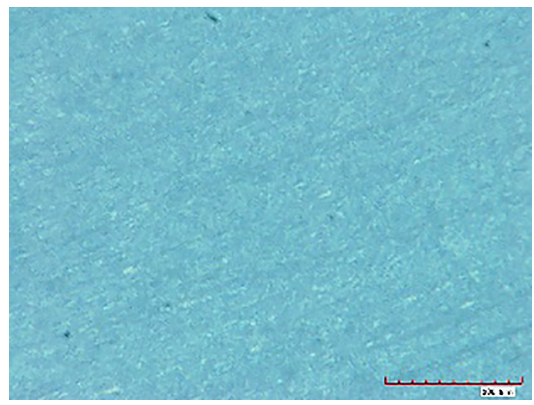

m) DB4 group

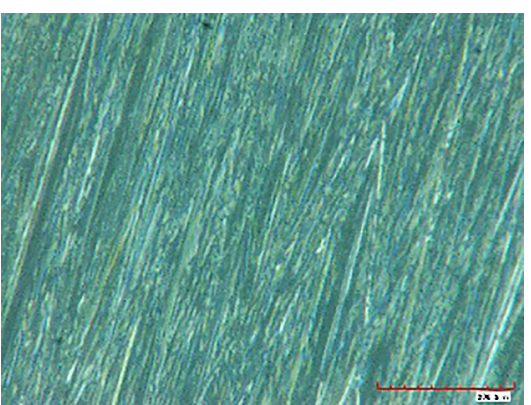

b) control (DCC) group

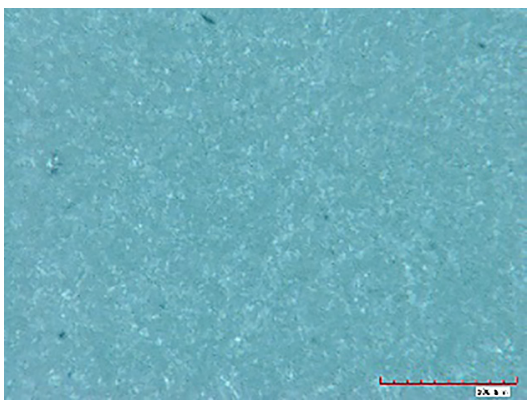

e) DC1 group

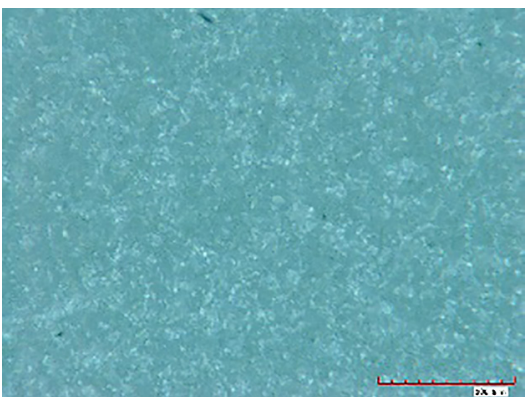

h) DC2 group

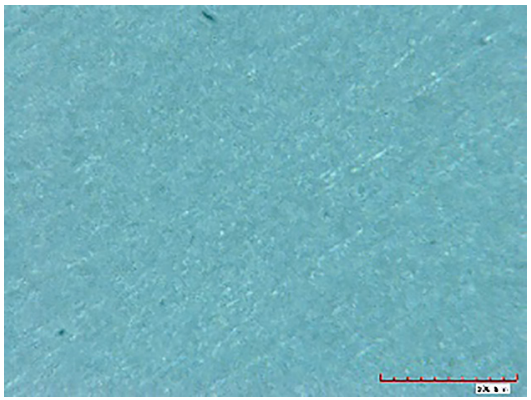

k) DC3 group

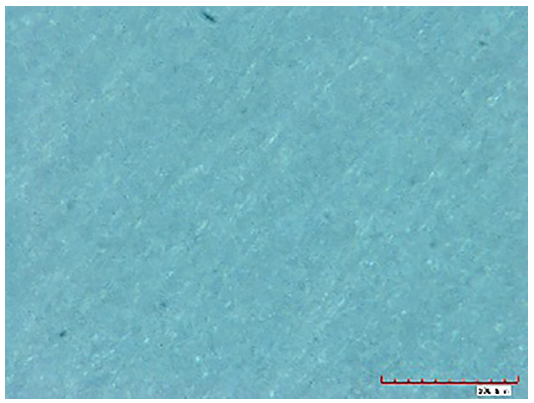

n) $\mathrm{DC} 4$ group

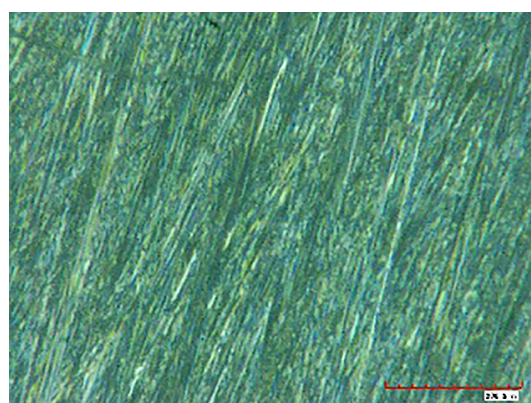

c) control (MLC) group

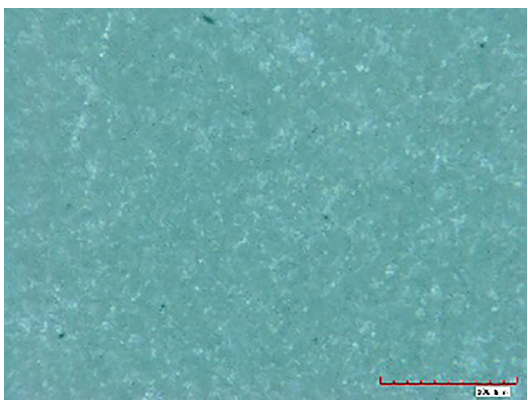

f) ML1 group

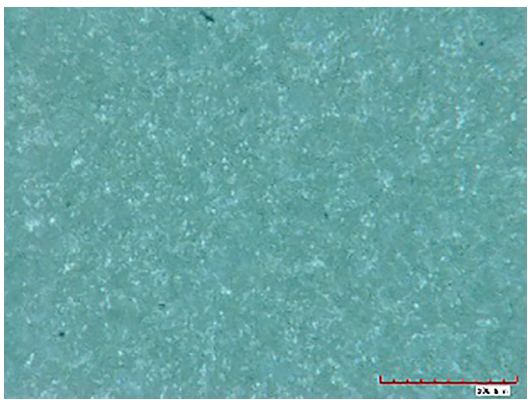

i) ML2 group

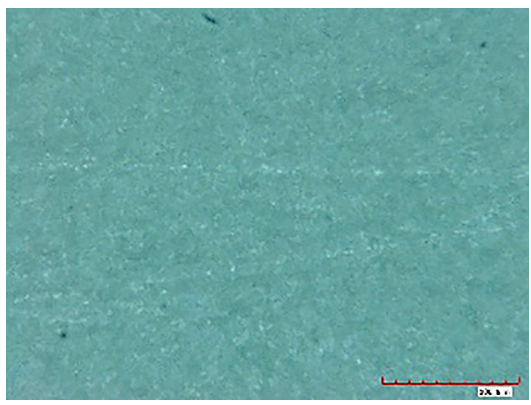

1) ML3 group

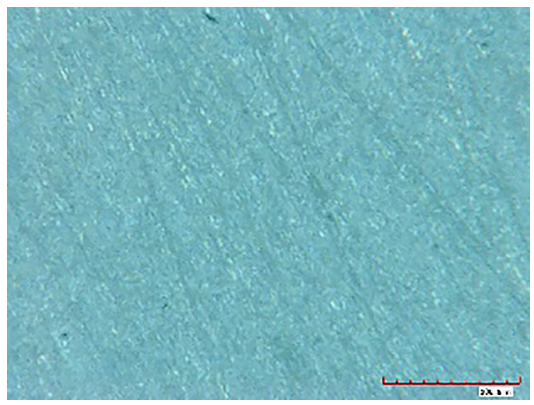

o) ML4 group

Figure 3. Surface micrographs of the different surface pre-treatment groups: more rougher surfaces were observed for groups treated with either the $50 \mu \mathrm{m}$ or $100 \mu \mathrm{m} \mathrm{Al}_{2} \mathrm{O}_{3}$ particles. 
particles $(2.954 \pm 0.266 \mu \mathrm{m}$ and $2.850 \pm 0.296 \mu \mathrm{m}$, respectively) and the lowest after the treatment with the $110-\mu \mathrm{m}$ glass microbeads $(0.413 \pm 0.126 \mu \mathrm{m}$ and 0.700 $\pm 0.118 \mu \mathrm{m}$, respectively) (see Figure 2).

The results of the ANOVA indicated that there were statistically significant differences in the surface roughness of the different surface pre-treatment groups $(p<0.05)$. In addition, the interaction effect between the various ceramic material groups and the various surface pre-treatment groups was also statistically significant $(p<0.05)$. Finally, the ANOVA also showed that there were statistically significant differences in the surface roughness of the surface pre-treatment groups for all the ceramic materials $(p<0.05)$ (see Table 3 ). The different surface pre-treatment groups were evaluated using a digital microscope (DIGITAL MICROSCOPE KH-7700, Hirox, Tokyo, Japan) at a magnification of $400 \times($ see Figure 3).

The mean $( \pm$ SD) SBS values of the DD Bio ZX2 (DB), DD Cube X2 (DC), and KATANA UTML (ML)

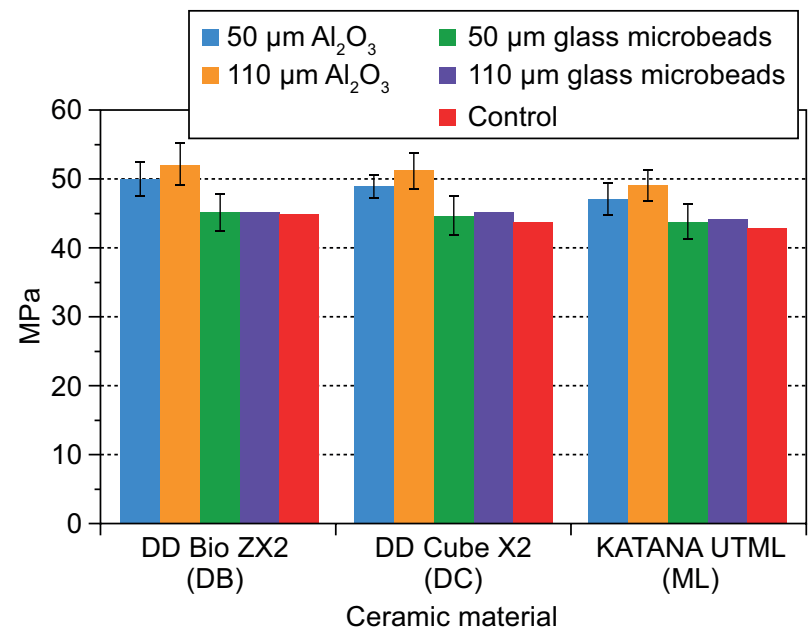

Figure 4. Mean shear bond strength (SBS) values (MPa) of the various experimental groups. samples subjected to the different pre-treatments could be arranged in the following order: $110-\mu \mathrm{m} \mathrm{Al}_{2} \mathrm{O}_{3}$ particles, $50-\mu \mathrm{m} \mathrm{Al}_{2} \mathrm{O}_{3}$ particles, $110-\mu \mathrm{m}$ glass microbeads, $50-\mu \mathrm{m}$ glass microbeads, and control (see Figure 4).

The two-way ANOVA showed that there were statistically significant differences in the SBS values of the various surface pre-treatment groups $(\mathrm{p}<0.05)$. In addition, the interaction effect between the ceramic material groups and the surface pre-treatment groups was also statistically significant $(\mathrm{p}<0.05)$. Moreover, the one-way ANOVA showed that there were statistically significant differences in the SBS values of the surface pre-treatment groups for all the ceramic materials $(\mathrm{p}<0.05)$ (see Table 4).

In the case of Katana UTML (ML), the surface treatments with the $50-\mu \mathrm{m}$ and $110-\mu \mathrm{m}$ glass microbeads were the ones most likely to result in an adhesive mode failure. On the other hand, the treatments with the $50-\mu \mathrm{m}$ and $110-\mu \mathrm{m} \mathrm{Al}_{2} \mathrm{O}_{3}$ particles were the ones most likely to result in a mixed mode failure. Moreover, this association was statistically significant $(\mathrm{p}<0.05)$ (see Table 5 ).

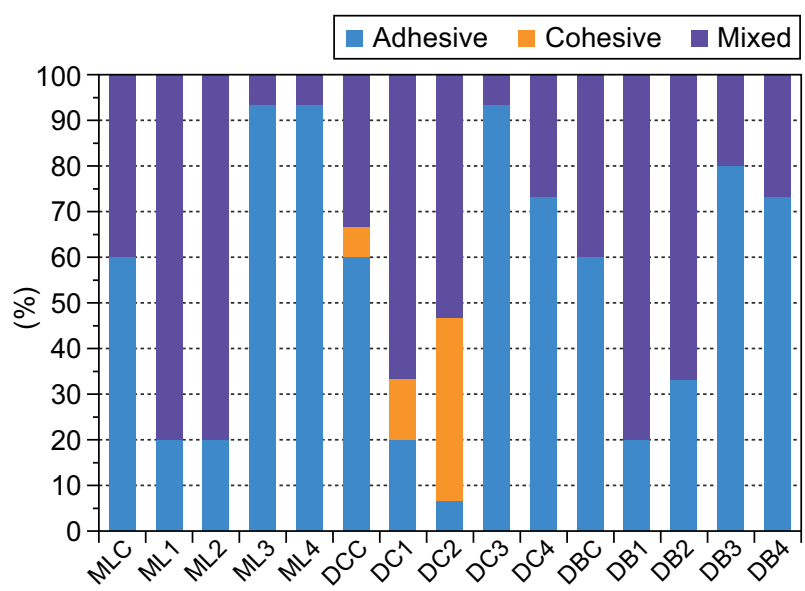

Figure 5. Failure modes of the resin cement-zirconia bonds after the various surface pre-treatments.

Table 4. Mean shear bond strength (SBS) (MPa) values of the different experimental groups.

\begin{tabular}{|c|c|c|c|c|c|c|c|}
\hline & & \multicolumn{2}{|c|}{ DD Bio ZX2 (DB) } & \multicolumn{2}{|c|}{ DD Cube X2 (DC) } & \multicolumn{2}{|c|}{ KATANA UTML (ML) } \\
\hline & & Mean difference & $\overline{p \text { value }}$ & Mean difference & $\overline{p \text { value }}$ & Mean difference & $\mathrm{p}$ value \\
\hline \multirow{4}{*}{$\begin{array}{l}50-\mu \mathrm{m} \mathrm{Al}_{2} \mathrm{O}_{3} \\
\text { particles }\end{array}$} & $100-\mu \mathrm{m} \mathrm{Al}_{2} \mathrm{O}_{3}$ particles & -2.17 & 0.124 & -2.21 & 0.167 & -2.04 & 0.399 \\
\hline & $50-\mu \mathrm{m}$ glass microbeads & $4.79^{*}$ & 0.000 & $4.34^{*}$ & 0.000 & $3.23^{*}$ & 0.045 \\
\hline & $110-\mu \mathrm{m}$ glass microbeads & $4.74^{*}$ & 0.000 & $3.82^{*}$ & 0.001 & 2.79 & 0.117 \\
\hline & Control & $4.98^{*}$ & 0.000 & $5.09^{*}$ & 0.000 & $4.04^{*}$ & 0.005 \\
\hline \multirow{3}{*}{$\begin{array}{l}110-\mu \mathrm{m} \mathrm{Al}_{2} \mathrm{O}_{3} \\
\text { particles }\end{array}$} & $50-\mu \mathrm{m}$ glass microbeads & $6.97^{*}$ & 0.000 & $6.55^{*}$ & 0.000 & $5.27^{*}$ & 0.000 \\
\hline & $110-\mu \mathrm{m}$ glass microbeads & $6.91^{*}$ & 0.000 & $6.03^{*}$ & 0.000 & $4.83^{*}$ & 0.000 \\
\hline & Control & $7.15^{*}$ & 0.000 & $7.31^{*}$ & 0.000 & $6.08^{*}$ & 0.000 \\
\hline \multirow{2}{*}{$\begin{array}{l}50-\mu \mathrm{m} \text { glass } \\
\text { microbeads }\end{array}$} & $110-\mu \mathrm{m}$ glass microbeads & -0.05 & 1.000 & -0.52 & 0.985 & -0.45 & 0.995 \\
\hline & Control & 0.19 & 1.000 & 0.75 & 0.941 & 0.81 & 0.957 \\
\hline $\begin{array}{l}110-\mu \mathrm{m} \text { glass } \\
\text { microbeads }\end{array}$ & Control & 0.24 & 0.999 & 1.27 & 0.698 & 1.25 & 0.817 \\
\hline
\end{tabular}

* Statistically significant at $P \leq 0.05$. 
Table 5. Failure mode during the shear bond strength (SBS) test.

\begin{tabular}{|c|c|c|c|c|c|c|}
\hline & & Control & $\begin{array}{c}50-\mu \mathrm{m} \mathrm{Al}_{2} \mathrm{O}_{3} \\
\text { particles }\end{array}$ & $\begin{array}{c}110-\mu \mathrm{m} \mathrm{Al}_{2} \mathrm{O}_{3} \\
\text { particles }\end{array}$ & $\begin{array}{l}50-\mu \mathrm{m} \text { glass } \\
\text { microbeads }\end{array}$ & $\begin{array}{c}110-\mu \mathrm{m} \text { glass } \\
\text { microbeads }\end{array}$ \\
\hline \multirow{2}{*}{ Katana UTML (ML) } & Adhesive & 9 & 3 & 3 & 14 & 14 \\
\hline & Mixed & 6 & 12 & 12 & 1 & 1 \\
\hline \multirow{3}{*}{ DD cube X2 (DC) } & Adhesive & 9 & 3 & 1 & 14 & 11 \\
\hline & Cohesive & 1 & 2 & 6 & 0 & 0 \\
\hline & Mixed & 5 & 10 & 8 & 1 & 4 \\
\hline \multirow{2}{*}{ DD Bio ZX2 (DB) } & Adhesive & 9 & 3 & 5 & 12 & 11 \\
\hline & Mixed & 6 & 12 & 10 & 3 & 4 \\
\hline
\end{tabular}

Note: Condition of the chi-squared test was not met (20\% of the cells should have an expected count of less than 5)

*Statistically significant at $P \leq 0.05$.

For DD cube X2 (DC), the surface treatment with the 50- $\mu \mathrm{m}$ glass microbeads was the one most likely to result in an adhesive mode failure, while the treatment with the $110-\mu \mathrm{m} \mathrm{Al}_{2} \mathrm{O}_{3}$ particles was the one most likely to result in a cohesive mode failure, and the treatment with the 50- $\mu \mathrm{m} \mathrm{Al}_{2} \mathrm{O}_{3}$ particles was the one most likely to result in a mixed mode failure. However, the conditions for the chi-squared test $(20 \%$ of the cells had an expected count of less than 5) were not met (Table 5). For DD Bio ZX2 (DB), the surface treatment with the $50-\mu \mathrm{m}$ glass microbeads was the one most likely to result in an adhesive mode failure while the treatment with the $50-\mu \mathrm{m} \mathrm{Al}_{2} \mathrm{O}_{3}$ particles was the one most likely to result in a mixed mode failure. Moreover, this association was also statistically significant $(\mathrm{p}<0.05)$ (see Table 5). Finally, all the failures could be classified either as adhesive, cohesive, or mixed (see Figure 5).

\section{DISCUSSION}

There have been several studies to improve the durability of the bonds formed between zirconia substrates and resin cements [11, 18, 19]. Among all the previously studied techniques, air particle abrasion combined with a chemical treatment results in the most durable bonds $[9,10]$. In the present study, air abrasion was performed using particles of two different types and sizes: abrasion with $\mathrm{Al}_{2} \mathrm{O}_{3}$ particles $(50$ and $110 \mu \mathrm{m})$ and glass microbeads $(50$ and $110 \mu \mathrm{m})$. Based on the results obtained, the first hypothesis was rejected because the surface roughness was affected by the different mechanical surface pretreatments evaluated.

Airborne particle abrasion can remove organic contaminants from the zirconia surface and increase its surface roughness, wettability, and surface free energy [20-22]. The results of the statistical analysis showed that the surface roughness of all the treated zirconia materials, that is, those treated using either the $\mathrm{Al}_{2} \mathrm{O}_{3}$ particles or the glass microbeads, increased. A previous study had also evaluated the effects of surface abrasion with $110-\mu \mathrm{m} \mathrm{Al}_{2} \mathrm{O}_{3}$ particles and found that the treatment increased the surface roughness of all four types of translucent zirconia materials tested [20]. Similar results were observed in the present study. In addition, in the present study, the surface abrasion with the $\mathrm{Al}_{2} \mathrm{O}_{3}$ particles $(50$ and $110 \mu \mathrm{m})$ resulted in a greater surface roughness than did the surface abrasion with the glass microbeads (50 and $110 \mu \mathrm{m})$. This result can be explained by the difference in the shapes of the particles used and their surface irregularities, since the glass microbeads used were microspheres while the $\mathrm{Al}_{2} \mathrm{O}_{3}$ particles were irregular; this increased the surface roughness of the treated zirconia samples [23-25]. Moreover, translucent zirconia tends to have a larger grain size. As a result, its grains are pulled out readily during the alumina abrasion process, resulting in large surface defects and, hence, increased surface roughness [26].

The second hypothesis was partially rejected because the SBS was affected by the abrasion with the $\mathrm{Al}_{2} \mathrm{O}_{3}$ particles $(50$ and $110 \mu \mathrm{m})$. However, no difference was observed between the control and zirconia groups abraded with the glass microbeads. Thus, it can be concluded that abrasion with airborne particles of $\mathrm{Al}_{2} \mathrm{O}_{3}$ results in higher mean SBS values than those of the other groups, with there being a difference between the values corresponding to the 50 - and $110-\mu \mathrm{m}$ particles. An in vitro study had reported similar findings and concluded that the absence of a surface treatment or air abrasion with glass microbeads resulted in lower SBS values for a resin cement bonded to different types of zirconia compared with the case for abrasion with airborne $\mathrm{Al}_{2} \mathrm{O}_{3}$ particles [21]. Therefore, abrasion with glass microbeads can be recommended for cleaning the surfaces of zirconia substrates instead of improving their bond strength with resin cement. However, another study had reported contradictory results, stating that the abrasion of zirconia surfaces with glass beads improved the bond strength of the surfaces with resin cement compared with the case for the untreated surfaces. Moreover, this was the case regardless of the technique used [27]. The results of the present study also indicated that the air abrasion of zirconia surfaces with $50-\mu \mathrm{m} \mathrm{Al}_{2} \mathrm{O}_{3}$ particles at a pressure of 2 bar results in the highest bond strength by promoting the micromechanical interlocking of the adhesive, increasing the surface roughness of the zirconia surface, and providing more hydroxyl groups for reacting with the primer [20, 22, 25, 28, 29]. 
To ensure long-term adhesion to zirconia, several studies have recommended the chemical treatment of the zirconia surfaces after air abrasion using a 10-MDP-containing primer or adhesive [20, 22, 24, 25, 28, 30, 31].

The hydrophobic phosphoric groups present in 10-MDP-based primers react with the hydroxyl groups on the surface of the translucent zirconia and enhance the bond strength [32]. In addition, the decyl group in 10-MDP prevents water penetration between the oxide layer of the translucent zirconia and the hydrophobic phosphate layer, resulting in a more stable resin bonding [33]. A study evaluated the effects of different priming agents, including the 10-MDP primer used in this study, on the SBS of a resin cement with translucent zirconia and found that the 10-MDP primer resulted in a higher post-thermocycling bond strength in the case of all the tested resin cements [31]. In addition, a recent review that compared the efficacies of different zirconia surface pre-treatments found that the mechanochemical treatment of zirconia surfaces with a 10-MDP primer and a self-adhesive resin cement resulted in the highest adhesive strength [34]. The use of highly translucent dual-curing resin cements is supported by other studies as they exhibit a greater degree of polymerisation and higher bond strength compared with those of opaque or self-curing resin cements $[31,35]$.

The limitations of the present study include the fact that we did not use different ceramic primers or resin-luting cements. In addition, the effects of the other treatment parameters, such as the air abrasion time and pressure, on the SBS were not investigated. Additional laboratory studies and clinical trials need to be conducted before any recommendations regarding the bonding of resin cement to highly translucent zirconia can be made.

\section{CONCLUSIONS}

Within the limitations of this study, the following conclusions can be drawn regarding translucent zirconia based on the results obtained:

- The air abrasion of the evaluated translucent zirconia surfaces with $50-\mu \mathrm{m} \mathrm{Al}_{2} \mathrm{O}_{3}$ particles at a pressure of 2 bar resulted in the most durable bonds (i.e., the highest SBS).

- The use of a 10-MDP-containing ceramic primer is recommended for improving the adhesion of resin cements to translucent zirconia ceramics.

\section{Acknowledgements}

This study was registered at and approved by the College of Dentistry Research Center (Registration number: $P R$ 0098). This manuscript is a part of a dissertation for $D S C D$.

\section{REFERENCES}

1. Zarone F., Russo S., Sorrentino R. (2011): From porcelainfused-to-metal to zirconia: clinical and experimental considerations. Dental Materials, 27, 83-96. doi: 10.1016/j. dental.2010.10.024

2. Rinke S., Fischer C. (2013): Range of indications for translucent zirconia modifications: clinical and technical aspects. Quintessence International, 44, 557-566.

3. Zhang, Y., Lawn, B. R. (2018): Novel zirconia materials in dentistry. Journal of Dental Research, 97, 140-147. doi: $10.1177 / 0022034517737483$

4. Tong H., Tanaka C.B., Kaiser M.R., Zhang Y. (2016): Characterization of three commercial Y-TZP ceramics produced for their high translucency. Ceramics International 42, 1077-1085. doi: 10.1016/j.ceramint.2015.09.033

5. Kwon S.J., Lawson N.C., Mclaren E.E., Nejat A.H., Burgess J.O. (2017): Comparison of the mechanical properties of translucent zirconia and lithium disilicate. Journal of Prosthetic Dentistry, 120, 132-137. doi: 10.1016/j.prosdent. 2017.08.004

6. Güth J.F., Stawarczyk B., EdelhoffD., LiebermannA. (2019): Zirconia, and its novel compositions: what do clinicians need to know? Quintessence International, 50, 512-520.

7. Mao L., Kaizer M.R., Zhao M., Guo B., Song Y.F., Zhang Y. (2019): Graded ultra-translucent zirconia (5Y-PSZ) for strength and functionalities. Journal of Dental Research, 9 , 1-7. doi: 10.1177/0022034518771287

8. Kern M. (2015): Bonding to oxide ceramics-laboratory testing versus clinical outcome. Dental Materials, 31, 8-14. doi: 10.1016/j.dental.2014.06.007

9. Inokoshi, M., De Munck, J., Minakuchi, S., Van Meerbeek, B. (2014): Meta-analysis of bonding effectiveness to zirconia ceramics. Journal of Dental Research, 93, 329-334. doi: 10.1177/0022034514524228

10. Ozcan M, Bernasconi M. (2015): Adhesion to zirconia used for dental restorations: a systematic review and metaanalysis. The Journal of Adhesive Dentistry, 17, 7-26.

11. Tanis, M.C., Akcaboy C. (2015): Effects of different surface treatment methods and MDP monomer on resin cementation of zirconia ceramics an in vitro study. Journal of Lasers in Medical Sciences, 6, 174-181. doi: 10.15171/ jlms.2015.15

12. Byeon S.M., Lee M.H., Bae T.S. (2017): Shear bond strength of $\mathrm{Al}_{2} \mathrm{O}_{3}$ sandblasted Y-TZP ceramic to the orthodontic metal bracket. Materials (Basel), 10, 148. doi: 10. 3390/ma10020148

13. Thompson J.Y., Stoner B.R., Piascik J.R., Smith R. (2011): Adhesion/cementation to zirconia and other non-silicate ceramics: where are we now? Dental Materials, 27, 71-82. doi: 10.1016/j.dental.2010.10.022

14. Tzanakakis E.G., Tzoutzas I.G., Koidis P.T. (2016): Is there a potential for durable adhesion to zirconia restorations? A systematic review. Journal of Prosthetic Dentistry, 115, 9-19. doi: 10.1016/j.prosdent.2015.09.008

15. San S., Phyo M., Takagaki T., Kham S. (2019): Effects of alumina-blasting pressure on the bonding to super/ultratranslucent zirconia. Dental Materials, 35, 730-739. Doi: 10.1016/j.dental.2019.02.025

16. Okutan Y., Yucel M.T., Gezer T., Donmez M.B. (2019): Effect of airborne particle abrasion and sintering order on the surface roughness and shear bond strength between Y-TZP ceramic and resin cement. Dental Materials Journal, 38, 241-249. doi: 10.4012/dmj.2018-051 
17. Martins S.B., Trindade Z. (2019): Does airborne-particle abrasion before, rather than after, zirconia sintering lead to higher mechanical strength even under aging challenge. Journal of Prosthetic Dentistry, 2019, 28, 1-8. doi: 10.1016/ j.prosdent.2018.10.022

18. Grasel R., Santos M.J., Chagas Rego H.M., Rippe M.E., Valandro L.F. (2018): Effect of resin luting systems and alumina particle air abrasion on bond strength to zirconia. Operative Dentistry, 43, 282-290. doi: 10.2341/15-352-L

19. Schnabl D., Dumfahrt H., Laimer J., Steinmassl O., Steinmassl P. (2020): Zirconia primers improve the shear bond strength of dental zirconia. Journal of Prosthodontics, 29, 62-68. doi: 10.1111/jopr.13013

20. Le M., Larsson C. Papia E. (2019): Bond strength between MDP-based cement and translucent zirconia. Dental Materials Journal, 38, 480-489. doi: 10.4012/dmj.2018-194.

21. Mehari K., Parke A.S., Gallardo F. F., Vandewalle K. S. (2020): Assessing the effects of air abrasion with aluminum oxide or glass beads to zirconia on the bond strength of cement. The Journal of Contemporary Dental Practice, 21, 713-717. doi: 10.5005/jp-journals-10024-2879

22. Yoshida K. (2020): Influence of alumina air-abrasion for highly translucent partially stabilized zirconia on flexural strength, surface properties, and bond strength of resin cement. Journal of Applied Oral Science, 28, 1-9. doi: 10. 1590/1678-7757-2019-0371.

23. Arao N., Yoshida K., Sawase T. (2015): Effects of air abrasion with alumina or glass beads on surface characteristics of CAD/CAM composite materials and the bond strength of resin cements. Journal of Applied Oral Science, 23, 629-636. doi: 10.1590/1678-775720150261

24. Colombo M., Gallo S., Padovan S., Chiesa M., Poggio C., Scribante A. (2020): Influence of different surface pretreatments on shear bond strength of an adhesive resin cement to various zirconia ceramics. Materials, 13, 1-13.

25. Lopes F.C., Palma-Dibb R. G., Campi L. B., Roselino R. F., Gomes E. A., Canevese V. A., Pereira G. K. R., Spazzin A. O., de Sousa-Neto M. D. (2018): Surface topography and bond strength of CAD - CAM milled zirconia ceramic luted onto human dentin: effect of surface treatments before and after sintering. Applied Adhesion Science, 6, 8. doi: 10.1186/s40563-018-0110-7

26. Pereira G.K.R., Guilardi L.F., Dapieve K.S., Kleverlaan C.J., Rippe M.P., Valandro L.F. (2018): Mechanical reliability, fatigue strength and survival analysis of new polycrystalline translucent zirconia ceramics for monolithic restorations. Journal of the Mechanical Behavior of Biomedical Materials, 85, 57-65. doi: 10.1016/j.jmbbm.2018.05.029

27. Martins A., Gotti V.B., Shimano M., Borges G., Gonçalves L. (2015): Improving adhesion between luting cement and zirconia-based ceramic with an alternative surface treatment. Brazilian Oral Research, 29, 1-2. doi: 10.1590/18073107BOR-2015.vol29.0054

28. Aung S.S.M.P., Takagaki T., Lyann S.K., Ikeda M., Inokoshi M., Sadr A., Nikaido T., Tagami J. (2019): Effects of alumina-blasting pressure on the bonding to super/ultratranslucent zirconia. Dental Materials, 35, 730-739. doi: 10.1016/j.dental.2019.02.025

29. Zhang X., Liang W., Jiang F., Wang Z., Zhao J., Zhou C., Wu J. (2021): Effects of air-abrasion pressure on mechanical and bonding properties of translucent zirconia. Clinical Oral Investigations, 25, 1979-1988. doi: 10.1007/ s00784-020-03506-y

30. Lima R.B.W., Barreto S.C., Alfrisany N.M., Porto T.S., De Souza G.M., De Goes M.F. (2019): Effect of silane and MDP-based primers on physico-chemical properties of zirconia and its bond strength to resin cement. Dental Materials, 35, 1557-1567. doi: 10.1016/j.dental.2019.07. 008

31. Yagawa S., Komine F., Fushiki R., Kubochi K., Kimura F., Matsumura H. (2018): Effect of priming agents on shear bond strengths of resin-based luting agents to a translucent zirconia material. Journal of Prosthodontic Research, 62, 204-209. doi: 10.1016/j.jpor.2017.08.011

32. Nagaoka N., Yoshihara K., Feitosa V.P., Tamada Y., Irie M., Yoshida Y., Van Meerbeek B., Hayakawa, S. (2017): Chemical interaction mechanism of 10-MDP with zirconia. Scientific Reports, 7, 45563. doi: 10.1038/srep45563

33. Feitosa V.P., Sauro S., Ogliari F.A., Ogliari A.O., Yoshihara K., Zanchi C.H., Correr-Sobrinho L., Sinhoreti M.A., Correr A.B., Watson T.F., Van Meerbeek B. (2014): Impact of hydrophilicity and length of spacer chains on the bonding of functional monomers. Dental Materials, 30, 317-323. doi: 10.1016/j.dental.2014.06.006

34. Comino-Garayoa R., Peláez J., Tobar C., Rodríguez V., Suárez M. J. (2012): Adhesion to zirconia: A systematic review of surface pretreatments and resin cements. Materials (Basel), 14, 2751. doi: 10.3390/ma14112751

35. Öztürk E., Bolay S., Hickel R., Ilie N. (2015): Effects of ceramic shade and thickness on the micro-mechanical properties of a light-cured resin cement in different shades. Acta Odontologica Scandinavica, 73, 503-507. doi: 10. 3109/00016357.2014.996185 